\title{
Hepatitis C virus-infected patients are 'spared' from the metabolic syndrome but not from insulin resistance. A comparative study of nonalcoholic fatty liver disease and hepatitis $C$ virus-related steatosis
}

\author{
Amedeo Lonardo $M D^{1}$, Stefano Ballestri $M D^{1}$, Luigi E Adinolfi $M D^{2}$, Enrico Violi $M D^{1}$, Lucia Carulli $M D P h D^{1}$, \\ Silvia Lombardini MD¹, Federica Scaglioni MD¹, Matteo Ricchi PhD¹, Giuseppe Ruggiero MD ${ }^{1}$, Paola Loria MD ${ }^{1}$
}

\begin{abstract}
A Lonardo, S Ballestri, LE Adinolfi, et al. Hepatitis C virusinfected patients are 'spared' from the metabolic syndrome but not from insulin resistance. A comparative study of nonalcoholic fatty liver disease and hepatitis $\mathrm{C}$ virus-related steatosis. Can J Gastroenterol 2009;23(4):273-278.
\end{abstract}

BACKGROUND: Nonalcoholic fatty liver disease (NAFLD) and chronic hepatitis $\mathrm{C}$ feature steatosis and insulin resistance (IR), conditions associated with the metabolic syndrome (MS).

OBJECTIVES: To assess the prevalence of MS and determinants of IR in patients with NAFLD and chronic hepatitis C.

METHODS: Ninety-three consecutive patients with NAFLD, 97 with chronic hepatitis $\mathrm{C}$ virus (HCV) genotypes 1 and 2, and 182 'healthy' controls without steatosis were enrolled in the present study. The prevalence of MS was assessed by modified Adult Treatment Panel III criteria and IR by the homeostasis model assessment of insulin resistance (HOMA-IR). IR was defined as the 75th percentile of the HOMA-IR of control subjects.

RESULTS: While the prevalence of IR was similar in NAFLD and HCV-infected subjects (70.0\% and $78.7 \%$, respectively), the prevalence of MS was significantly higher in NAFLD patients than in HCV-infected patients (27.9\% versus $4.1 \%$ ) and in controls (5.6\%). With multivariate analysis, IR was predicted by body mass index (OR $1.263 ; 95 \%$ CI 1.078 to 1.480 ) and triglyceridemia (OR $1.011 ; 95 \%$ CI 1.002 to 1.020 ) in NAFLD and by sex (OR for female sex 0.297 ; $95 \%$ CI 0.094 to 0.940 ) and fibrosis stage (OR 2.751; 95\% CI 1.417 to 5.340) in chronic hepatitis C.

CONCLUSIONS: IR is independently associated with body mass index and triglyceridemia in NAFLD, sex and fibrosis in chronic $\mathrm{HCV}$ infection, and has a higher prevalence in NAFLD and chronic hepatitis $\mathrm{C}$ than in controls. However, the frequency of MS in HCVinfected patients, similar to that of controls, is significantly lower than that seen in NAFLD patients. The current diagnostic criteria of MS are more likely to 'capture' patients with NAFLD than with chronic hepatitis $\mathrm{C}$, although both groups are insulin resistant.

Key Words: Body mass index; Fibrosis; HCV; HOMA-IR; Insulin resistance; Metabolic syndrome; Nonalcoholic fatty liver disease; Sex; Steatosis; Triglycerides;
Des patients infectés par le virus de l'hépatite $\mathrm{C}$ sont «épargnés " par le syndrome métabolique mais non par l'insulinorésistance. Une étude comparative de la stéatose hépatique non alcoolique et de la stéatose liée au virus de l'hépatite $\mathrm{C}$

HISTORIQUE : La stéatose hépatique non alcoolique (SHNA) et l'hépatite C chronique comprennent une stéatose et une insulinorésistance (IR), des troubles reliés au syndrome métabolique (SM).

OBJECTIFS : Évaluer la prévalence du SM et les déterminants de l'IR chez les patients atteints d'une SHNA ou d'une hépatite $\mathrm{C}$ chronique. MÉTHODOLOGIE : Quatre-vingt-treize patients consécutifs atteints de SHNA, 97 patients présentant les génotypes 1 et 2 du virus d'hépatite $C$ chronique (VHC) et 182 sujets témoins en santé sans stéatose ont participé à la présente étude. Les auteurs ont évalué la prévalence de SM selon les critères modifiés de l'Adult Treatment Panel III et celle de l'IR par l'évaluation du modèle d'homéostasie de l'insulinorésistance (HOMAIR). L'IR était définie comme le $75^{\mathrm{e}}$ percentile de l'HOMA-IR des sujets témoins.

RÉSULTATS : La prévalence d'IR était similaire chez les sujets atteints de SHNA et chez ceux infectés par le VHC $(70,0 \%$ et $78,7 \%$, respectivement), mais la prévalence de SM était considérablement plus élevée chez les patients atteints de SHNA que chez ceux infectés par le VHC $(27,9 \%$ par rapport à $4,1 \%)$ et chez les sujets témoins $(5,6 \%)$. À l'analyse multivariée, il était possible de prédire l'IR par l'indice de masse corporelle (RRR 1,263; $95 \%$ IC 1,078 à 1,480) et la triglycéridémie (RRR 1,$011 ; 95$ \% IC 1,002 à 1,020) en cas de SHNA, et par le sexe (RRR pour les sujets de sexe féminin 0,$297 ; 95 \%$ IC 0,094 à 0,940 ) et la phase de la fibrose (RRR 2,751; $95 \%$ IC 1,417 à 5,340) en cas d'hépatite C chronique.

CONCLUSIONS : L'IR s'associe de manière indépendante à l'IMC et à la triglycéridémie en cas de SHNA, et au sexe et à la fibrose en cas d'infection par le VHC chronique, et sa prévalence est plus élevée en cas de SHNA et d'hépatite $\mathrm{C}$ chronique que chez les sujets témoins. Cependant, la fréquence de SM chez les patients infectés par le VHC, similaire à celle des sujets témoins, est considérablement plus basse que chez les patients atteints de SHNA. Les critères diagnostiques actuels du SM sont plus susceptibles de « repérer » les patients atteints de SHNA que d'hépatite $\mathrm{C}$ chronique, même si les deux groupes sont insulinorésistants.

adjustments stemming from impaired tissue response to the many insulin actions, represents the precursor of type 2 diabetes in predisposed individuals. IR and/or its histological correlate, steatosis, are common determinants of liver disease progression in both NAFLD (4-6) and HCV infection (7).

prominent features (3). IR, which spans the gamut of biological

${ }^{1}$ Università degli Studi di Modena e Reggio Emilia, Dipartimento di Medicina, Endocrinologia e Geriatria, Modena; ${ }^{2}$ Università degli Studi di

Napoli, Dipartimento di Medicina Interna, Napoli, Italy

Correspondence: Dr Amedeo Lonardo, Nuovo Ospedale Civile S Agostino, Estense di Baggiovara, Via Giardini 1355 Baggiovara, Modena 41100 ,

Italy. Telephone 39-059-396-1806, fax 39-059-396-2577, e-mail a.lonardo@libero.it

Received for publication June 23, 2008. Accepted November 25, 2008 
First proposed in 2003 (3), the theory that hepatic steatosis observed in the setting of HCV infection might be better interpreted on the grounds of our understanding of the pathogenesis of NAFLD has paved the way to a novel line of research of comparative studies between these two common liver diseases (8-12). In this connection, our recent study (8) comparing NAFLD, HCV-related steatosis and familial hypobetalipoproteinemia patients showed that "not all hepatic fat is alike" and that the etiology of steatosis makes an important difference in the development of IR.

Although two recent studies $(9,11)$ address the predictors of fibrosis in NAFLD and HCV, no previous studies have comparatively evaluated the predictors of IR in NAFLD and HCV infection, and definitive conclusions cannot be drawn concerning this issue. Moreover, IR is the pathogenic hallmark of the metabolic syndrome (MS), and liver steatosis represents the hepatic manifestation of MS. Thus, whether the etiology of IR may have a different impact on MS remains unknown.

Given the pivotal pathogenic role of IR in the steatogenesis and natural history of fatty liver disorders, the present study evaluated IR, MS and predictors of IR comparatively in a large series of patients with NAFLD, HCV infection and 'healthy' controls. The specific aim was to assess the role of steatosis of different etiology in modulating the prevalence of diseases belonging to the domain of MS, and to describe the predictors of IR in NAFLD and HCV-infected patients. Considering that HCV genotype 3 has a direct steatogenic effect independent of IR (13), to avoid confounding factors (14), we studied only patients infected with HCV genotypes 1 and 2.

\section{METHODS}

General study design

A total of 372 subjects were enrolled at two participating centres: The Academic Liver Clinic at the Baggiovara Hospital, Modena, Italy, and the Department of Internal Medicine and Hepatology at the Second University of Naples, Ospedale Gesù e Maria, Naples, Italy. These 372 subjects comprised three groups of individuals: healthy controls, patients with NAFLD and patients with HCV infection. In these three groups, the prevalence of the individual components of MS were assessed and the determinants of IR, defined as the 75th percentile of the homeostasis model assessment of insulin resistance (HOMA-IR) in control subjects (15), were studied.

\section{Patients}

Nonsteatototic 'healthy' controls: One hundred eighty-two outpatient subjects (131 from Modena and 51 from Naples) were selected for the present study. This group was extracted from a larger population of blood donors with a low probability of hepatic steatosis according to the modified criteria described by Szczepaniak et al (16) and modified by us. Briefly, the criteria for inclusion were normal liver enzymes, absence of 'bright liver' at ultrasound scan, alcohol consumption of less than $30 \mathrm{~g} /$ day for men and less than $20 \mathrm{~g} /$ day for women, a body mass index (BMI) of less than $35 \mathrm{~kg} / \mathrm{m}^{2}$ and a fasting glucose level of less than $7 \mathrm{mmol} / \mathrm{L}$.

NAFLD: Ninety-three consecutive patients with NAFLD were enrolled. Of these, 78 were participating in the Policentrica Steatosi Epatica Non Alcolica project in Modena, Italy. The protocol of the study has been detailed elsewhere (17). In brief, general practitioners in Modena, Italy, were invited to refer their cases of recently diagnosed bright liver. Each subject underwent further evaluation. The remaining 15 NAFLD patients were recruited in Naples, Italy, with a similar protocol.
Criteria for the diagnosis of NAFLD were presence of bright liver at ultrasound scan diagnosed by liver-kidney contrast as described elsewhere (17); compatible histological findings (18); and low to absent alcohol consumption (less than $30 \mathrm{~g} /$ day for men and less than $20 \mathrm{~g} /$ day for women). Exclusion criteria were chronic hepatitis due to toxic or drug-induced, viral, autoimmune, hemodynamic or genetic-metabolic causes evaluated by hepatitis surface antigen positivity, HCV antibodies, antinuclear antibody, smooth muscle antibody, anti-liver kidney microsomal antibody, alpha-1 antitrypsin, and ceruloplas$\mathrm{min}$ and transferrin saturation assays.

Chronic hepatitis $\mathrm{C}$ naive: Ninety-seven consecutive patients (27 from Modena and 70 from Naples) with chronic hepatitis C were included in the present study. The inclusion criteria were the following: increased aminotransferase levels (greater than 1.5 times normal) for at least six months, presence of anti-HCV and HCV RNA in serum, HCV genotypes 1 and 2, and compatible liver biopsy for chronic hepatitis C. Patients who were hepatitis B surface antigen- and/or HIV-positive and had other potential causes of liver disease, such as excessive alcohol intake (more than $30 \mathrm{~g} /$ day) or features of autoimmunity (eg, autoimmune hepatitis, primary biliary cirrhosis, sclerosing cholangitis) or metabolic liver disease (hemochromatosis, Wilson's disease), were excluded. Patients with severe cardiac or renal disease, or active intravenous drug abuse were also excluded. None of the patients had received previous treatment with interferon or immunosuppressive agents, or were taking medication that could cause steatosis (ie, salicylates, nonsteroidal anti-inflammatory drugs, corticosteroids, valproic acid, amiodarone, perhexiline maleate).

\section{Evaluation of alcohol consumption}

Alcohol consumption was assessed through patient interviews conducted by two different physicians, and validated through interviews with relatives and referring physicians.

\section{Anthropometric and blood pressure measurements}

Patients were weighed and their height recorded by trained personnel with standardized procedures. BMI was calculated as weight $(\mathrm{kg})$ divided by height squared $\left(\mathrm{m}^{2}\right)$. Waist girth was measured in $\mathrm{cm}$ with a tape measure at navel level. Blood pressure was recorded with the patient supine with the Riva-Rocci/ Korotkoff technique.

\section{Laboratory evaluation}

Blood samples were taken after an overnight fast, usually early in the morning before liver biopsy. Laboratory evaluation included liver function tests, renal function, blood cell count, metabolic profiling (serum total and fractionated cholesterol, triglycerides, fasting glucose and insulin, serum uric acid), thyroid stimulating hormone and a thyroxine-free blood test. All tests were performed by experienced technicians with commercially available kits.

HCV RNA-positivity was evaluated with the Amplicor HCV test kit (Roche Diagnostics SpA, Italy); viral load was evaluated with a polymerase chain reaction test kit (Monitor HCV-Amplicor; Roche Diagnostics SpA, Italy); and viral genotyping was determined by a reverse hybridization probe assay (Inno-Lipa, Microgen, Germany) as previously described (13).

The presence of insulin resistance was evaluated through HOMA-IR using the formula:

Fasting insulin $(\mu \mathrm{lU} / \mathrm{mL}) \times$ fasting glucose $(\mathrm{mmol} / \mathrm{L}) / 22.5$ 
TABLE 1

Demographic, anthropometric, clinical, laboratory and histological patient data

\begin{tabular}{|c|c|c|c|c|}
\hline Variable & Controls (n=182) & NAFLD (n=93) & $\begin{array}{c}\text { Chronic hepatitis } C \\
\text { genotypes } 1 \text { and } 2 \quad(n=97)\end{array}$ & $P^{*}$ \\
\hline Age, years & $47.00(36.50,56.50)(169)$ & $47(36,56)(93)$ & $53.00(43.50,57.50)(97)$ & 0.025 \\
\hline Body mass index, $\mathrm{kg} / \mathrm{m}^{2}$ & $23.93(21.79,25.95)(167)$ & $28.52(26.14,32.20)(90)$ & $25.65(24.20,28.00)(94)$ & $<0.001$ \\
\hline Waist girth, $\mathrm{cm}$ & - & $100.44 \pm 10.71(61)$ & $88.02 \pm 10.06(68)$ & $<0.001$ \\
\hline Maximum arterial blood pressure, $\mathrm{mmHg}$ & $130.00(110.00,140.00)(71)$ & $125(120,130)(65)$ & $120(110,130)(71)$ & 0.013 \\
\hline Minimum arterial blood pressure, $\mathrm{mmHg}$ & $80.00(75.00,90.00)(71)$ & $80(80,80)(65)$ & $80(70,80)(71)$ & 0.002 \\
\hline Alanine aminotransferase ( $\mu \mathrm{Kat} / \mathrm{L})$ & $0.30(0.27,0.37)(93)$ & $0.54(0.44,0.84)(90)$ & $1.38(1.03,2.10)(95)$ & $<0.001$ \\
\hline Aspartate aminotransferase ( $\mu \mathrm{Kat} / \mathrm{L})$ & $0.27(0.20,0.37)(182)$ & $1.04(0.74,1.75)(84)$ & $1.07(0.78,1.82)(95)$ & $<0.001$ \\
\hline Gamma-glutamyl transpeptidase ( $\mu \mathrm{Kat} / \mathrm{L})$ & $0.25(0.18,0.35)(181)$ & $0.85(0.53,1.36)(82)$ & $0.77(0.55,1.27)(96)$ & $<0.001$ \\
\hline Uric acid, $\mu \mathrm{mol} / \mathrm{L}$ & $244.72 \pm 71.98(181)$ & $353.46 \pm 87.44(91)$ & $290.58 \pm 57.70(92)$ & $<0.001$ \\
\hline Cholesterol, $\mathrm{mmol} / \mathrm{L}$ & $5.29 \pm 1.01(182)$ & $5.51 \pm 1.25(92)$ & $4.60 \pm 0.98(97)$ & $<0.001$ \\
\hline Triglycerides, mmol/L & $1.28(0.90,1.54)(182)$ & $1.68(1.21,2.38)(92)$ & $1.02(0.86,1.38)(97)$ & $<0.001$ \\
\hline Fasting glucose, $\mathrm{mmol} / \mathrm{L}$ & $4.80(4.38,5.33)(178)$ & $5.30(4.88,5.72)(92)$ & $5.22(4.66,5.72)(97)$ & $<0.001$ \\
\hline Fasting insulin, pmol/L & $59.73(38.89,82.64)(163)$ & $94.80(68.06,132.44)(84)$ & $111.12(75.70,185.08)(97)$ & $<0.001$ \\
\hline $\begin{array}{l}\text { Homeostasis model of assessment for insulin } \\
\text { resistance }\end{array}$ & $1.78(1.18,2.66)(159)$ & $3.17(2.21,5.16)(83)$ & $3.79(2.61,6.15)(97)$ & $<0.001$ \\
\hline Steatosis & - & $40(25,70)(88)$ & $5(0,25)(97)$ & $<0.001$ \\
\hline Inflammatory score & - & $3(2,4)(73)$ & $1(0,2)(97)$ & $<0.001$ \\
\hline Fibrosis score & - & $0(0,1)(91)$ & $2(1,3)(97)$ & $<0.001$ \\
\hline
\end{tabular}

Data presented as mean (25th percentile, 75th percentile [for data not normally distributed]) (n); *P values refer to multiple comparisons. NAFLD Nonalcoholic fatty liver disease

The cut-off value for normal HOMA-IR was set at the 75th percentile of the healthy control group's HOMA-IR $(8,15)$. Hepatitis B virus, HIV markers and autoimmunity were determined by commercially available kits.

\section{Modified Adult Treatment Panel III criteria for metabolic syndrome}

The Adult Treatment Panel III (ATP III) criteria for the diagnosis of MS (19) include the presence of at least three derangements among arterial hypertension (greater than $130 / 85 \mathrm{mmHg}$ ); fasting glucose level of $6.1 \mathrm{mmol} / \mathrm{L}$ or greater; waist girth greater than $102 \mathrm{~cm}$ for men and greater than $88 \mathrm{~cm}$ for women; serum triglyceride levels $1.7 \mathrm{mmol} / \mathrm{L}$ or higher; high-density lipoprotein (HDL) serum cholesterol level less than $1.03 \mathrm{mmol} / \mathrm{L}$ (men) or less than $1.29 \mathrm{mmol} / \mathrm{L}$ (women).

Given that waist girth and serum HDL cholesterol values were not available in all cases, BMI (more than $30 \mathrm{~kg} / \mathrm{m}^{2}$ ) and total cholesterol $(5.17 \mathrm{mmol} / \mathrm{L}$ or higher) were used, respectively, as surrogate indexes. Diabetes was considered to be present in individuals being treated with antidiabetic agents or who had fasting blood glucose levels of $7 \mathrm{mmol} / \mathrm{L}$ or higher on two occasions in the absence of any such treatments.

\section{Histological evaluation}

After obtaining written consent from the patients, liver biopsy specimens were sampled under ultrasound guidance via subcostal route. To be considered significant, liver samples had to include at least six portal tracts. In NAFLD, liver histology was evaluated according to Brunt's criteria (18). The diagnosis of nonalcoholic steatotic hepatitis (NASH) required the following histological features: steatosis, parenchymal inflammation and ballooning degeneration of hepatocytes with or without fibrosis, and Mallory bodies (18). Given that steatosis is not an 'all or none phenomenon', this histological feature was described as a continuous variable rather than as 'present/absent' both in NAFLD and in chronic hepatitis $\mathrm{C}$ patients. In the latter disease, necroinflammatory score was determined according to Knodell et al (20), and fibrosis stage according to Scheuer (21).

\section{Statistical analysis}

The distribution of variables was evaluated using the nonparametric Kolmogorov-Smirnov procedure. The results have been expressed as mean \pm SE for normally distributed variables and as median (25th percentile, 75 th percentile) for the variables not normally distributed. The latter were subjected to mathematical computer-aided transformation. Differences among means in the groups were analyzed with one-way statistical procedure (post hoc Scheffe's test) and ANCOVA (analysis of covariance). The Kruskall-Wallis test was used to evaluate the differences between the groups for ordinal variables. The relationship between HOMA-IR and the other variables was evaluated with the Spearman's correlation. Logistic regression analysis was used to identify the classifying variables of IR. $\mathrm{P}<0.05$ was considered to be statistically significant. For the statistical analysis, the SPSS program for Windows v14.0.0 (SPSS Inc, USA) was used.

\section{RESULTS}

To exclude the possibility of bias, a preliminary comparative evaluation of the data between the two participating centres was performed. No significant differences were found in any of the parameters studied among comparable groups between the two centres. Thus, the data from the two centres were pooled and evaluated together. In the NAFLD group, we found a majority of cases with NASH, the proportion of those with pure fatty liver being $31 \%$ (data not shown).

The descriptive data of the 372 subjects included in the present study are shown in Table 1 and Figure 1 . There were 


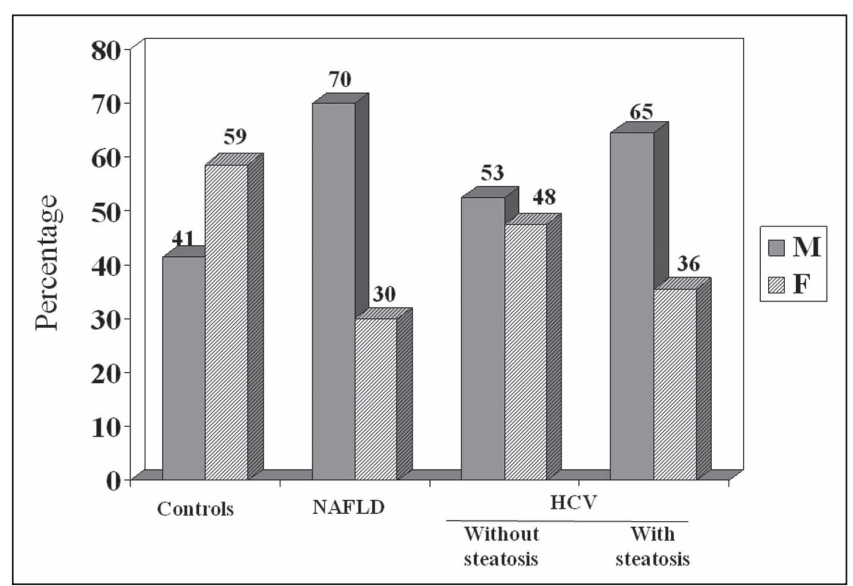

Figure 1) Proportion of men and women in the control, nonalcoholic fatty liver disease (NAFLD) and hepatitis $\mathrm{C}$ virus (HCV)-positive patient groups. Steatosis due to NAFLD appears to be strikingly prevalent in men, as is steatosis associated with $\mathrm{HCV}$ infection. In contrast, in patients with $\mathrm{HCV}$ infection without steatosis, there is a substantial similarity in the prevalence of men versus women. Overall, the proportion of men is statistically highly significant in the various groups $(P<0.001)$. M Male; F Female

significant differences between the NAFLD, HCV and control groups in all parameters evaluated (Table 1). In particular, NAFLD patients showed significantly higher BMI, waist girth, serum cholesterol and triglycerides, and steatosis grade than HCV patients. The proportion of men was greater both in NAFLD and in HCV. However, the prevalence of men in those with HCV with steatosis was much higher than in those without steatosis.

The prevalence of MS and related parameters in the three study groups is reported in Table 2 . In general, the metabolic disorders are significantly more prevalent in patients with NAFLD than in those with HCV infection (Table 2). However, there was no significant difference between NAFLD and HCV patients in the prevalence of hyperglycemia (19.6\% versus $17.5 \%)$, and there was a trend for a higher prevalence of hypertension in HCV patients (24\% versus $16.9 \%$ ).

The prevalence of fasting hyperglycemia (fasting glucose of $6.11 \mathrm{mmol} / \mathrm{L}$ or higher) in $\mathrm{HCV}$ patients $(17.5 \%)$ was higher than in controls $(6.7 \%)$, ranking in the same order of magnitude as NAFLD patients (19.6\%). The prevalence of hypercholesterolemia and hypertriglyceridemia was significantly higher in patients with NAFLD than in those with HCV infection (59.8\% versus $17.5 \%$, respectively; $\mathrm{P}=0.001$ )
(Table 2). Similarly, the prevalence of obesity (ie, BMI $30 \mathrm{~kg} / \mathrm{m}^{2}$ or higher) was significantly higher in NAFLD patients than in those with HCV infection $(34.4 \%$ versus $12.4 \%$, respectively; $\mathrm{P}=0.001$ ) (Table 2). Taken collectively, according to the ATP III modified criteria, the prevalence of MS was significantly higher in NAFLD than in HCV and in healthy controls $(27.9 \%$ versus $4.1 \%$ versus $5.5 \%$, respectively; $\mathrm{P}=0.001$ ) (Table 2 ).

To assess the prevalence and independent predictors of IR, a logistic regression analysis was performed for NAFLD and HCV patients. A HOMA-IR value of greater than 2.6659, corresponding to the 75 th percentile of the healthy controls value, was used as the dependent variable. All parameters evaluated in the patients and reported in Table 1 were used as independent variables. Age, sex and BMI were entered into the statistical analysis as covariates. As reported in Table 3, the prevalence of IR in NAFLD patients was $70 \%$ and the independent factors associated were BMI and triglycerides (Table 3). The prevalence of IR in HCV-infected patients was 78.7\% (Table 4). There was no difference in the prevalence of IR among HCV genotype 1 and 2 . The univariate analysis for HCV-infected patients revealed that the variables associated with IR were steatosis extent, fibrosis stage, inflammatory grade and HCV viral load. With multivariate analysis, male sex and fibrosis stage were independently associated with IR in this series of HCV-infected patients (Table 4). These same variables predicted IR when the analysis was limited to patients with HCV and steatosis more than $5 \%$ alone (data not shown).

\section{DISCUSSION}

Our study has three major findings: the low prevalence of MS in $\mathrm{HCV}$, the determinants of IR among NAFLD and HCV patients, and the association of steatosis with the male sex.

\section{MS}

A high prevalence of IR, which is a hallmark of MS, was observed in both NALFD and HCV-infected patients (70\% and $78.7 \%$, respectively). Despite this, the two liver diseases under scrutiny display a significantly different prevalence of MS, as low in HCV-positive patients as in selected healthy controls - $4.1 \%$ versus $5.5 \%$, respectively - versus $27.9 \%$ among NAFLD patients. Stated otherwise, the present study demonstrates that, although they are indeed insulin resistant, HCV patients are spared from the development of MS. In contrast, IR observed in the setting of NAFLD has a significant connection with the development of the MS. In the few previously published studies (10-12), the ratio of the prevalence of MS in NASH to the prevalence of MS in HCV has been found to range from 2 to 8 (Table 5). We included all the NAFLD

\section{TABLE 2}

Prevalence of metabolic syndrome and its components

\begin{tabular}{|c|c|c|c|c|c|}
\hline Condition*, n (\%) & Controls $(n=182)$ & $\begin{array}{c}\text { Nonalcoholic fatty liver } \\
\text { disease }(n=93)\end{array}$ & $\begin{array}{c}\text { Chronic hepatitis C } \\
\text { genotypes } 1 \text { and } 2(n=97)\end{array}$ & $\mathbf{P}^{\dagger}$ & $\chi^{2}$ \\
\hline Obesity & $7(4.2)$ & $31(34.4)$ & $12(12.4)$ & $<0.001$ & 44.046 \\
\hline Hypercholesterolemia & $95(52.2)$ & 55 (59.8) & $17(17.5)$ & $<0.001$ & 41.514 \\
\hline Hypertriglyceridemia & $29(15.9)$ & $44(47.8)$ & $12(12.4)$ & $<0.001$ & 43.452 \\
\hline Hyperglycemia & $12(6.7)$ & $18(19.6)$ & $17(17.5)$ & 0.003 & 11.562 \\
\hline Arterial hypertension & $34(47.9)$ & $11(16.9)$ & $17(24.0)$ & $<0.001$ & 17.366 \\
\hline Metabolic syndrome & $10(5.5)$ & $26(27.9)$ & $4(4.1)$ & $<0.001$ & 21.682 \\
\hline
\end{tabular}

*Diagnostic Criteria: Obesity: Body mass index $\geq 30 \mathrm{~kg} / \mathrm{m}^{2}$; Hypercholesterolemia: Total cholesterol $\geq 5.17 \mathrm{mmol} / \mathrm{L}$; Hypertriglyceridemia: Serum triglyceride levels $\geq 1.7 \mathrm{mmol} / \mathrm{L}$; Hyperglycemia: Taking glucose-lowering drugs or fasting glucose $\geq 6.1 \mathrm{mmol} / \mathrm{L}$ in the absence of any such treatments; Arterial hypertension: Taking antihypertensive drugs or arterial blood pressure $\geq 130 / 85 \mathrm{mmHg}$ in the absence of any such treatments. ${ }^{\dagger}$ Refers to multiple comparisons 
TABLE 3

Prevalence and predictors of insulin resistance in nonalcoholic fatty liver disease

\begin{tabular}{|c|c|c|c|c|c|c|}
\hline Variable & B & SE & $\mathbf{P}$ & OR & $95 \% \mathrm{Cl}$ & $\begin{array}{c}\text { Overall } \\
\text { correct, \% }\end{array}$ \\
\hline Age & 0.017 & 0.026 & 0.505 & 1.018 & 0.967-1.071 & \\
\hline Sex & -1.061 & 0.687 & 0.123 & 0.346 & 0.090-1.331 & \\
\hline Body mass index & 0.233 & 0.081 & 0.004 & 1.263 & $1.078-1.480$ & 70.0 \\
\hline Triglycerides & 0.011 & 0.004 & 0.014 & 1.011 & $1.002-1.020$ & \\
\hline Constant & -8.649 & 2.640 & 0.001 & 0.000 & - & \\
\hline
\end{tabular}

TABLE 4

Prevalence and predictors of insulin resistance in hepatitis C-naive genotype 1 or 2

\begin{tabular}{|c|c|c|c|c|c|c|}
\hline Variable & B & SE & $\mathbf{P}$ & OR & $95 \% \mathrm{Cl}$ & $\begin{array}{c}\text { Overall } \\
\text { correct, \% }\end{array}$ \\
\hline Age & 0.042 & 0.030 & 0.154 & 1.043 & $0.984-1.105$ & \\
\hline Body mass index & 0.085 & 0.071 & 0.232 & 1.089 & $0.947-1.251$ & \\
\hline Female & -1.213 & 0.587 & 0.039 & 0.297 & $0.094-0.940$ & 78.7 \\
\hline Staging & 1.012 & 0.338 & 0.003 & 2.751 & $1.417-5.340$ & \\
\hline Constant & -4.607 & 2.393 & 0.054 & 0.010 & - & \\
\hline
\end{tabular}

\section{TABLE 5}

Prevalence of the metabolic syndrome assessed through the Adult Treatment Panel III criteria for nonalcoholic fatty liver disease (NAFLD), hepatitis C virus (HCV) and control group in published studies

\begin{tabular}{|c|c|c|c|c|c|}
\hline \multirow[b]{2}{*}{ Author (reference) } & \multirow[b]{2}{*}{ Series (NAFLD/HCV) } & \multirow[b]{2}{*}{ NAFLD, \% } & \multicolumn{3}{|c|}{ Metabolic syndrome } \\
\hline & & & HCV, \% & NAFLD/HCV ratio & Controls, \% \\
\hline Targher et al (10) & $60 / 60$ & $52.05^{\star}$ & 25. & 2.1 & 0.0 \\
\hline Svegliati-Baroni et al (11) & $90 / 90$ & 22.2 & 4.4 & 5.04 & NA \\
\hline Tsochatzis et al (12) & $176 / 95$ & $41.3^{*}$ & 5.1 & 8.09 & NA \\
\hline Present study ${ }^{\dagger}$ & $93 / 97$ & 27.9 & 4.1 & 6.38 & 5.5 \\
\hline
\end{tabular}

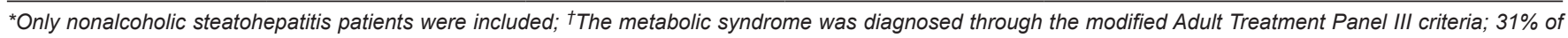
patients had pure fatty liver. NA Not addressed

patients rather than those with NASH alone, and we used BMI rather than waist girth to calculate the prevalence of MS. In spite of these methodological differences, the results of the present study found a ratio of 6.38 between the prevalence of MS in NAFLD and in HCV-infected patients (Table 5). This ratio falls within the range reported by other authors (10-12). This finding confirms that HCV is associated with IR rather than with the MS. Hence, the definition of a peculiar HCVassociated dysmetabolic syndrome has been proposed (22). Our findings may be clinically relevant. Patients with chronic hepatitis C rarely manifest fullblown MS as presently defined, although they are insulin resistant. This implies that either specific criteria for MS in patients with HCV infection should be envisaged or, alternatively, importance should be given to the demonstration of IR as a diagnostic criterion of MS.

\section{Determinants of IR}

The independent predictors of IR are also different for NALFD and HCV-infected patients. Although previous studies $(9,11)$ reported an independent association between hepatic fibrosis and IR on the one hand, and MS on the other, our study followed a different approach. We addressed the determinants of IR rather than those of fibrosis in both NAFLD (not NASH alone) and HCV. What we found is that BMI and serum levels of triglycerides are independently associated with IR in NAFLD patients, whereas, male sex and histological fibrosis are associated with IR in HCV genotypes 1- or 2infected patients. It is well known that BMI and triglycerides are independent correlates of NAFLD (23). The data in the present study show that the same determinants that apply to the development of NAFLD are also associated with IR, and support the role of IR in the process of steatogenesis. Little is known about the differential impact of varying HCV genotypes (7). In the present study, we studied HCV genotypes 1 and 2 together. However, a recent paper (24) suggested that for similar analyses, genotype 1 may be grouped with genotype 4, while genotype 2 may be grouped with genotype 3 . According to this paper, the analysis of genotype 1 and $2 \mathrm{HCV}$-infected patients together might therefore not be appropriate for studying the association with IR. However, our study was planned and performed largely before the publication of that study (24) and we believe additional data are needed before any ultimate conclusion can be drawn regarding the role of HCV genotypes in IR. Host (ie, steatosis) $(25,26)$ and viral factors (high viral load and viral genotypes 1 and 4 in IR linked to HCV infection $[24,27,28]$ ) have recently been reported to predict IR in HCV infection. Our study demonstrated that fibrosis predicts IR in our HCV patients and is also compatible with these previous reports given that steatosis is a well known precursor of fibrosis $(13,26)$, and that high viral load is a risk factor for histological liver damage (29).

Role of sex

Ancillary findings of our study include that steatosis - metabolic (ie, NAFLD) and HCV-related - is prevalent among men. While the prevalence of male sex in NAFLD is universally accepted (30), data concerning sex prevalence in HCV-related steatosis are more controversial. Poynard et al (31) reported a 
male prevalence among those with steatosis. Cammà et al (32) reported that female sex is associated with moderate to severe steatosis. However, the finding that in chronic hepatitis $\mathrm{C}$, the probability of fibrosis F2-F4 was lower for menopausal women receiving hormone replacement therapy, and that steatosis was more frequent and more severe in menopausal women (33), adds further evidence to the specific role of estrogens in the progression of HCV-related liver disease.

The present study may have some limitations related to the modified diagnostic criteria of MS and the choice, as the control group, of healthy nonsteatosic subjects who, by enrollment criteria, encompass a group at low risk for MS. This may have lowered the bar for HOMA-IR in an average-risk general population and thus, the results cannot be universally applied to the general population, but maintain their value in the specific series reported here.

\section{CONCLUSION}

Our study shows the prevalence of MS to be significantly higher in patients with NAFLD than that observed in subjects with chronic hepatitis $\mathrm{C}$, although both conditions feature steatosis and a high prevalence of IR. This latter point was related to anthropometric (BMI) and metabolic (triglycerides) derangements in NAFLD but not in chronic hepatitis C patients, in whom other factors (eg, sex and fibrosis score) seem to play a major role. The prevalence of MS in HCVinfected patients was similar to that of healthy nonsteatotic control subjects. Given that the current criteria for the diagnosis of MS are based on anthropometric and metabolic measurements, the results of the present study explain the apparent paradox that chronic hepatitis $\mathrm{C}$ patients, although often insulin resistant, are seemingly 'spared' from MS.

ACKNOWLEDGEMENTS: English revision of the manuscript by Ms Jacqueline Mole is gratefully acknowledged.

\section{REFERENCES}

1. Kotronen A, Westerbacka J, Bergholm R, Pietiläinen KH, Yki-Järvinen $\mathrm{H}$. Liver fat in the metabolic syndrome. J Clin Endocrinol Metab 2007;92:3490-7.

2. Ratziu V, Heurtier A, Bonyhay L, Poynard T, Giral P. Review article: An unexpected virus-host interaction - the hepatitis $C$ virusdiabetes link. Aliment Pharmacol Ther. 2005;22(Suppl 2):56-60.

3. Lonardo A, Adinolfi LE, Loria P, Carulli N, Ruggiero G, Day CP. Steatosis and hepatitis $\mathrm{C}$ virus: Mechanisms and significance for hepatic and extrahepatic disease. Gastroenterology 2004:126:586-97.

4. Friis-Liby I, Aldenborg F, Jerlstad P, Rundstrom K, Bjornsson E. High prevalence of metabolic complications in patients with nonalcoholic fatty liver disease. Scand J Gastroenterol 2004;39:864-9.

5. Angulo P, Hui JM, Marchesini G, et al. The NAFLD fibrosis score: A noninvasive system that identifies liver fibrosis in patients with NAFLD. Hepatology 2007;45:846-54.

6. Adams LA, Lymp JF, St Sauver J, et al. The natural history of nonalcoholic fatty liver disease: A population-based cohort study. Gastroenterology 2005;129:113-21.

7. Lonardo A, Carulli N, Loria P. HCV and diabetes. A two-questionbased reappraisal. Dig Liver Dis 2007;39:753-61.

8. Lonardo A, Lombardini S, Scaglioni F, et al. Hepatic steatosis and insulin resistance: Does etiology make a difference? J Hepatol 2006; 44:190-6.

9. Bugianesi E, Marchesini G, Gentilcore E, et al. Fibrosis in genotype 3 chronic hepatitis $\mathrm{C}$ and nonalcoholic fatty liver disease: Role of insulin resistance and hepatic steatosis. Hepatology 2006:44:1648-55.

10. Targher G, Bertolini L, Padovani R, Rodella S, Arcaro G, Day C. Differences and similarities in early atherosclerosis between patients with non-alcoholic steatohepatitis and chronic hepatitis B and C. J Hepatol 2007;46:1126-32.

11. Svegliati-Baroni G, Bugianesi E, Bouserhal T, et al. Post-load insulin resistance is an independent predictor of hepatic fibrosis in virus $\mathrm{C}$ chronic hepatitis and in non-alcoholic fatty liver disease. Gut 2007;56:1296-301.

12. Tsochatzis E, Patheodoridis GV, Manesis EK, Kafiri G, Tiniakos DG, Archimandritis AJ. Metabolic syndrome is associated with severe fibrosis in chronic viral hepatitis and non-alcoholic steatohepatitis. Aliment Pharmacol Ther 2008;27:80-9.

13. Adinolfi LE, Gambardella M, Andreana A, Tripodi MF, Utili R, Ruggiero G. Steatosis accelerates the progression of liver damage of chronic hepatitis $\mathrm{C}$ patients and correlates with specific HCV genotype and visceral obesity. Hepatology 2001;33:1358-64.

14. Adinolfi LE. Hepatitis $C$ and fatty liver. In: Negro F, ed. Hot Topics in Viral Hepatitis, Hepatitis C and Metabolism, 2nd edn. Modena: FB Communication, 2006:21-9.

15. Balkau B, Charles MA. Comments on the provisional report from the WHO consultation. Diabet Med 1999;16:442-3.

16. Szczepaniak LS, Nurenberg P, Leonard D, et al. Magnetic resonance spectroscopy to measure hepatic triglyceride content: Prevalence of hepatic steatosis in the general population. Am J Physiol Endocrinol Metab 2005;288:E462-8.

17. Lonardo A, Loria P, Leonardi F, et al. Fasting insulin and uric acid levels but not indices of iron metabolism are independent predictors of non-alcoholic fatty liver disease. A case-control study. Dig Liver Dis 2002;34:204-11.

18. Brunt EM. Nonalcoholic steatohepatitis. Semin Liver Dis 2004;24:3-20.

19. Grundy SM, Brewer HB Jr, Cleeman JI, Smith SC Jr, Lenfant C; American Heart Association; National Heart, Lung, and Blood Institute. Definition of metabolic syndrome: Report of the National Heart, Lung, and Blood Institute/American Heart Association conference on scientific issues related to definition. Circulation 2004;109:433-8.

20. Knodell RG, Ishak KG, Black WC, et al. Formulation and application of a numerical scoring system for assessing histological activity in asymptomatic chronic active hepatitis. Hepatology 1981;1:431-5.

21. Scheuer PJ. Scoring of liver biopsies: Are we doing it right? Eur J Gastroenterol Hepatol 1996;8:1141-3.

22. Lonardo A, Loria P. The hepatitis $C$ virus-associated dysmetabolic syndrome. Hepatology 2008;48:1018-9.

23. Farrell GC, Larter CZ. Nonalcoholic fatty liver disease: From steatosis to cirrhosis. Hepatology 2006;43(2 Suppl 1):S99-S112.

24. Moucari R, Asselah T, Cazals-Hatem D, et al. Insulin resistance in chronic hepatitis C: Association with genotypes 1 and 4, serum HCV RNA level, and liver fibrosis. Gastroenterology 2008;134:416-23

25. Fartoux L, Poujol-Robert A, Guéchot J, Wendum D, Poupon R, Serfaty L. Insulin resistance is a cause of steatosis and fibrosis progression in chronic hepatitis C. Gut 2005;54:1003-8.

26. Vidali M, Tripodi M-F, Ivaldi A, et al. Interplay between oxidative stress and hepatic steatosis in the pathogenesis of chronic hepatitis C. J Hepatol 2008;48:399-406.

27. Yoneda M, Saito S, Ikeda T, et al. Hepatitis C virus directly associates with insulin resistance independent of the visceral fat area in nonobese and nondibaetic patients. J Viral Hepat 2007;14:600-7.

28. Hsu CS, Liu CJ, Liu CH, et al. High hepatitis $\mathrm{C}$ viral load is associated with insulin resistance in patients with chronic hepatitis C. Liver Int 2008;28:271-7.

29. Adinolfi LE, Utili R, Andreana A, et al. Serum HCV RNA levels correlate with histological liver damage and concur with steatosis in progression of chronic hepatitis C. Dig Dis Sci 2001;46:1677-83.

30. Lonardo A, Carani C, Carulli N, Loria P. 'Endocrine NAFLD' a hormonocentric perspective of nonalcoholic fatty liver disease pathogenesis. J Hepatol 2006;44:1196-207.

31. Poynard T, Cacoub P, Ratziu V, et al. Fatigue in patients with chronic hepatitis C. J Viral Hepat 2002;9:295-303.

32. Cammà C, Bruno S, Di Marco V, et al. Insulin resistance is associated with steatosis in nondiabetic patients with genotype 1 chronic hepatitis C. Hepatology 2006;43:64-71.

33. Codes L, Asselah T, Cazals-Hatem D, et al. Liver fibrosis in women with chronic hepatitis C: Evidence for the negative role of the menopause and steatosis and the potential benefit of hormone replacement therapy. Gut 2007;56:390-5. 


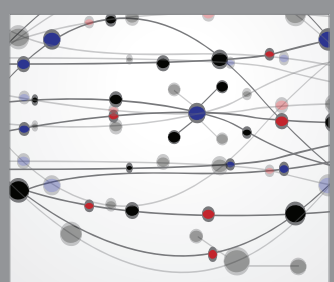

The Scientific World Journal
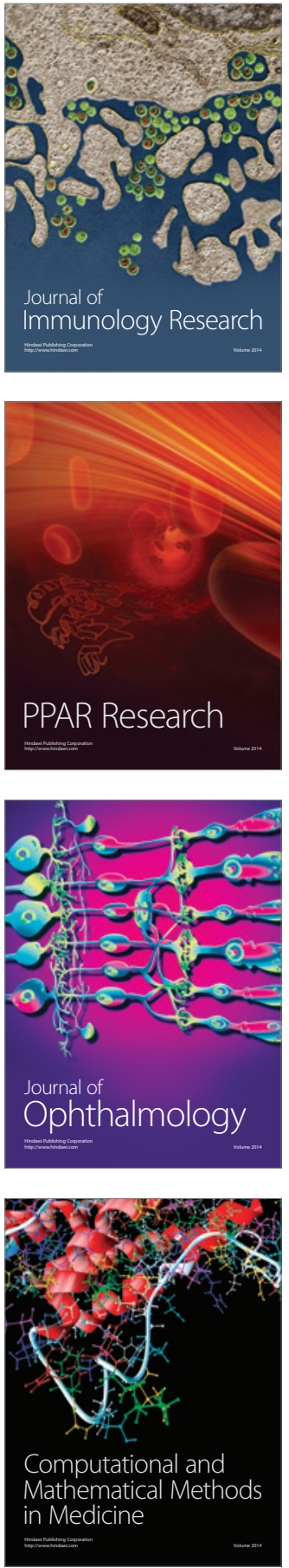

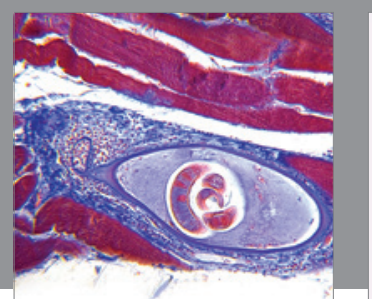

Gastroenterology Research and Practice

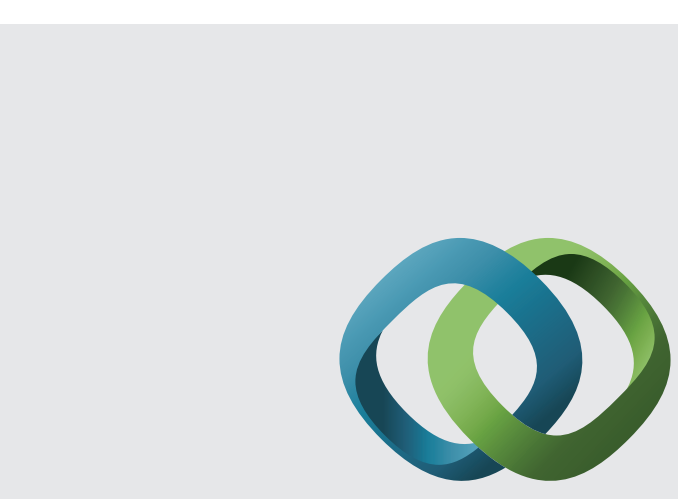

\section{Hindawi}

Submit your manuscripts at

http://www.hindawi.com
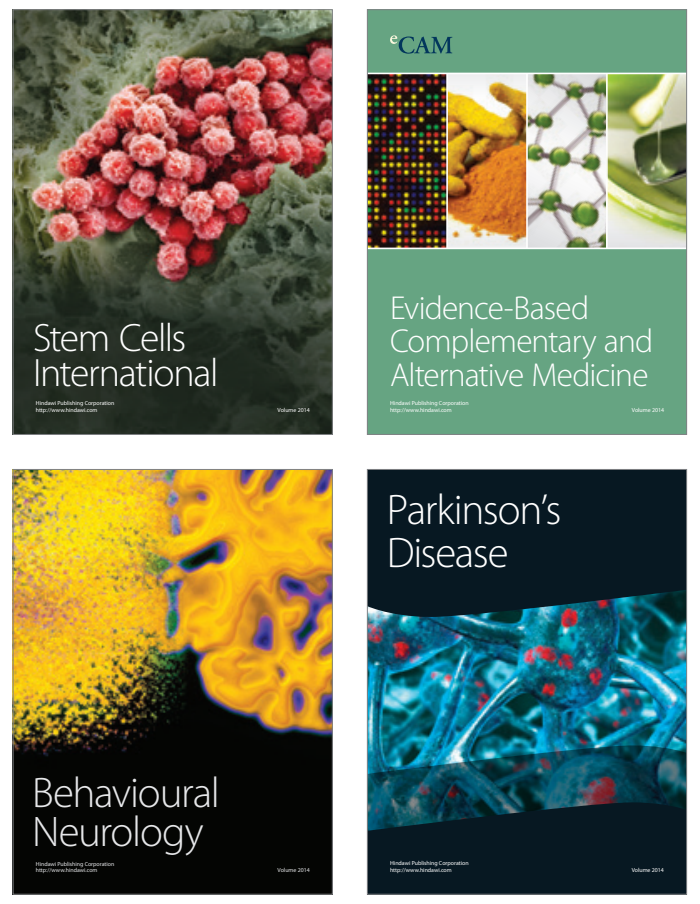
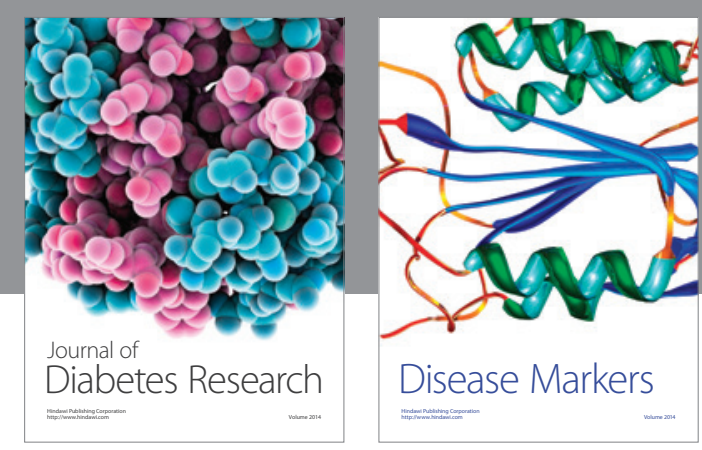

Disease Markers
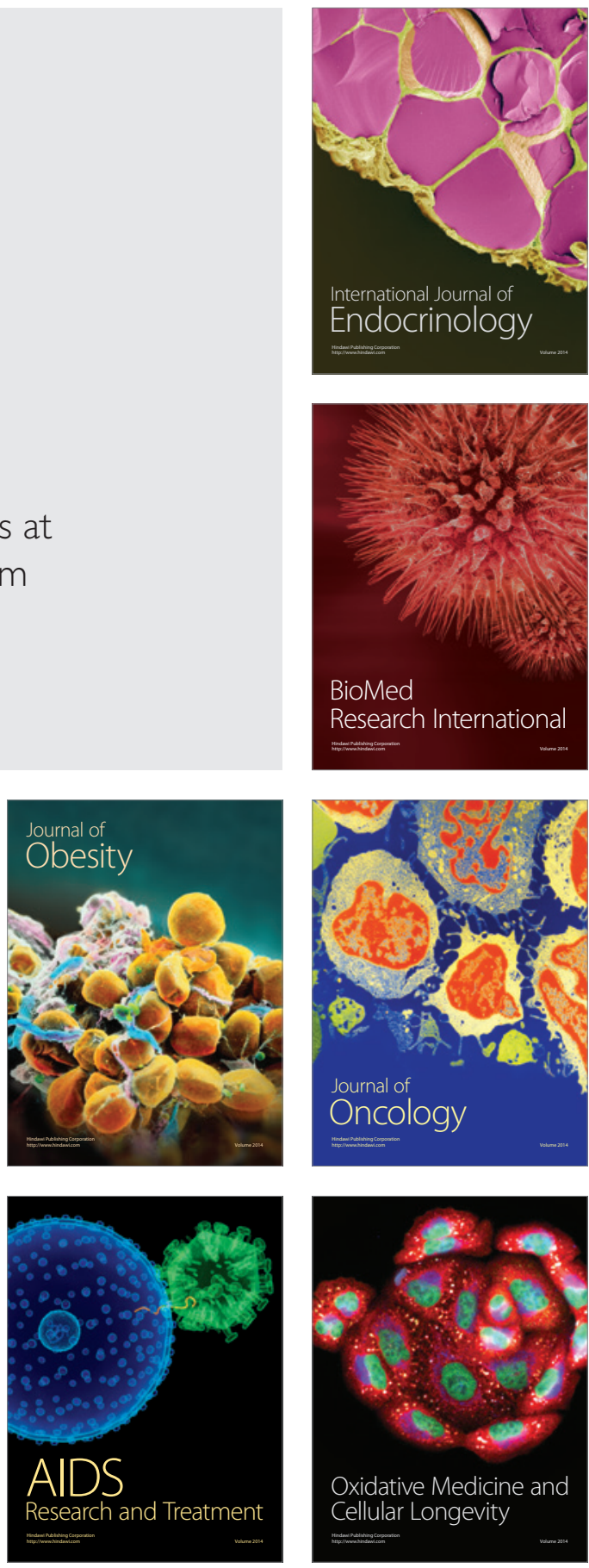